\title{
Male bats respond to adverse conditions with larger colonies and increased torpor use during sperm production
}

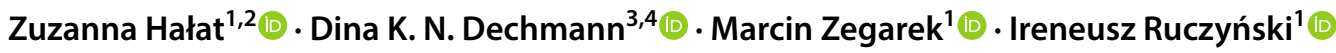

Received: 12 February 2020 / Accepted: 18 September 2020 / Published online: 28 October 2020

(c) The Author(s) 2020

\begin{abstract}
Changes in environmental conditions can have strong energetic effects on animals through limited food availability or increased thermoregulatory costs. Especially difficult are periods of increased energy expenditures, such as reproduction. Reproductive female bats from the temperate zone often aggregate in maternity colonies to profit from social thermoregulation to reduce torpor use and buffer the effects of poor conditions. The much rarer male colonies may form for similar reasons during testes development. Male colonies thus allow us to study the influence of environmental conditions on energy budget and colony size, without the confounding effects of parental care. We remotely monitored skin temperature and assessed colony size of male parti-coloured bats Vespertilio murinus during summer, and correlated those variables with environmental conditions and food availability (i.e. insect abundance). As we had hypothesized, we found that colony size increased at colder temperatures, but decreased at low wind speeds. Also as predicted, torpor use was relatively low, however, it did increase slightly during adverse conditions. Male sociality may be an adaptation to adverse environmental conditions during sexual maturation, but the pressure to avoid torpor during spermatogenesis may be lower than in pregnant or lactating females.
\end{abstract}

Keywords Group size $\cdot$ Sociality $\cdot$ Spermatogenesis $\cdot$ Thermoregulation $\cdot$ Vespertilio murinus

\section{Introduction}

Environmental conditions such as temperature, humidity, salinity, or photoperiod, have a strong influence on all living organisms. Many animals have evolved adaptations allowing them to survive and reproduce when conditions fluctuate outside their optimal range (Begon et al. 2005).

Handling editor: Danilo Russo.

Electronic supplementary material The online version of this article (https://doi.org/10.1007/s42991-020-00071-5) contains supplementary material, which is available to authorized users.

Zuzanna Hałat

zuzahalat@ibs.bialowieza.pl

1 Mammal Research Institute, Polish Academy of Sciences, Stoczek 1, 17-230, Białowieża, Poland

2 Faculty of Biology, University of Warsaw, Miecznikowa 1, 02-096 Warszawa, Poland

3 Department of Migration, Max Planck Institute of Animal Behavior, Am Obstberg 1, 78315 Radolfzell, Germany

4 Department of Biology, University of Konstanz, Universitätsstrasse 10, 78457 Konstanz, Germany
Common adaptations to seasonal changes include migration, hibernation, seasonal breeding, and moulting (Ruf et al. 2012). Small endothermic animals with their high surface to volume ratio and often high metabolisms, can be affected by seasonal or even daily fluctuations in conditions particularly strongly (McNab 1983; Boyles et al. 2007; Boratyński et al. 2018). This is especially pronounced in small insectivorous mammals, because short-term changes in weather impact them not only directly, but also through their effect on insect occurrence. Insects are very vulnerable to environmental conditions and insect abundance is significantly higher at high ambient temperatures and low wind speeds (Williams 1961; Ruczyński et al. 2020). The resulting large fluctuations in insect availability thus require corresponding adaptations by insectivorous animals to balance their energy budget. Insectivorous bats are a good model for investigating these processes, as their expensive mode of locomotion puts them under high energetic pressure (Alexander 2002). Especially during energetically costly reproduction (Lane et al. 2010) bats have to increase caloric intake while they reduce use their main energy saving strategy, torpor, as it interferes with foetal development, milk, and sperm production (Racey and Swift 1981; Kurta and Kunz 1988; Entwistle et al. 1998; 
Wilde et al. 1999; Dietz and Kalko 2006; Komar et al. 2020). High blood testosterone level further prevents torpor use in reproductive males (Speakman and Thomas 2003).

Consequently, bats are particularly sensitive to adverse environmental conditions and prey scarcity during the breeding season (Racey and Speakman 1987). Even though reproduction in temperate zone bats is timed with the period of highest insect abundance, short-term fluctuations can be quite dramatic and make behavioural and/or physiological adaptations necessary (Anthony and Kunz 1977; Ruczyński et al. 2020). Two main strategies have been proposed to buffer the effect of lower insect availability and bad weather during reproduction in temperate zone bats: living in colonies and social foraging. Female bats of many species form colonies to benefit from social warming and reduce torpor use during the breeding season (Tuttle and Stevenson 1982; Kerth 2008; Pretzlaff et al. 2010; Terrien et al. 2011). Clustered females of little brown bat (Myotis lucifugus) have lower metabolic rates than solitary individuals under the same conditions (Kurta et al. 1987) and female Daubenton's bats (Myotis daubentonii) use social thermoregulation to compensate high energy demands of reproduction (Dietz and Kalko 2006). Pup development, too, is dependent on roost temperature during foetal development and after parturition (Racey and Swift 1981; Kerth et al. 2001).

In contrast, males of most temperate zone bat species are solitary during the time when females form breeding colonies. However, male sociality has evolved independently several times, always in highly specialized open aerial foragers, who depend on swarming insects, which are unpredictable in space and have a short daily window of occurrence (Safi and Kerth 2007; Ruczyński et al. 2020). It has been hypothesized that males form colonies to avoid torpor during spermatogenesis (Safi 2008). They would then profit from social thermoregulation, similar to the females, as torpor slows down sperm production (Entwistle et al. 1998) and even food restricted males avoid torpor during this time (Komar et al. 2020). In addition, males may profit from increased foraging success through passive information transfer during the energetically demanding spermatogenesis (Safi 2008). By flying within earshot of colony members and using information contained in the echolocation calls they inadvertently produce (feeding buzzes), bats may find the insect swarms they depend on more efficiently (Dechmann et al. 2009, 2010; Cvikel et al. 2015; Gager 2019). This may allow them to more rapidly develop their reproductive tissues, which can become $40 \%$ larger during the mating period (Krutzsch 2000). Males which have reached a high level of reproductive tissue development, leave colonies earlier, potentially to avoid supporting future mating competitors or establish good mating territories (Safi 2008). Once sperm production is completed, sperm is moved to the epididymes. After this, torpor supports sperm storage, reducing or even eliminating the need for normothermy (Racey 1972; Geiser and Brigham 2012), and potentially explaining why males become solitary again at this point. However, to what extent colonial males use these strategies during sexual maturation remains largely untested.

The objective of our study was to assess the behavioural and physiological response of male bats to changes in environmental conditions, i.e. weather and food availability, during testes development. The parti-coloured bat (Vespertilio murinus) is one of the few Palaearctic species, where males also briefly form colonies, consisting of up to 250 individuals during summer (Rydell and Baagøe 1994). We observed colonies in Białowieża Primaeval Forest from the beginning of June until the 9th of July. This period fully overlapped with the development of reproductive tissues, as confirmed by the progressive filling of the epididymes (Krutzsch 2000; Safi 2008; Hałat et al. 2018; Komar et al. 2020). Colony size ranged from 46 to just a few or even single individuals during this period (Hałat et al. 2018). We hypothesized that male parti-coloured bats should form larger groups and reduce torpor even during colder, rainy, and windy days, as well as days with low insect abundance. The evolutionary mechanisms that shape colony size during sperm production and maturation would then be weather conditions. If alternatively, males seek out roosts with specific microclimates under certain ambient conditions, we expected to see a link between temperature and specific roosts. With this study we aimed to investigate the response of social male bats to environmental conditions, and identify the evolutionary factors, driving males of only a few temperate zone bat species to aggregate in colonies during summer.

\section{Materials and methods}

Our study was conducted in June and July of 2016 and 2017 in the Polish part of the Białowieża Primaeval Forest $\left(52^{\circ} 45^{\prime} 8^{\prime \prime} \mathrm{N}, 23^{\circ} 52^{\prime} 45^{\prime \prime} \mathrm{E}\right)$. This overlapped with sexual development of male parti-coloured bats (Hałat et al. 2018; Komar et al. 2020).

\section{Environmental data and insect abundance}

We obtained weather data (temperature at $2 \mathrm{~m}$ above ground, precipitation, wind) from the local weather station in Białowieża. We estimated insect abundance with a camera survey (for details see Ruczyński et al. 2020). Briefly, we placed cameras (WG-5 GPS Ricoh Imaging Company Ltd. Tokyo, Japan) on $2 \mathrm{~m}$-high poles, with the lens directed towards the sky. Photos were taken from sunset to sunrise at 5 min intervals. As we do not know, where parti-coloured bats exactly forage, we placed the cameras in three different habitat types, to gain a good overview of insect abundance. 
We surveyed insects in this manner during 10 nights with 18 cameras (six cameras per habitat type) in 2016 and during 54 nights with nine cameras (three cameras per habitat type) in 2017. To account for the difference in number of sites between the years, we always used the mean number of insects for all possible combinations including always three sites per habitat for any given night during analyses (Hałat et al. 2018; Ruczyński et al. 2020).

\section{Capture and roost localizations}

We caught male parti-coloured bats (Vespertilio murinus) with a harp trap, a funnel trap or mist nets, depending on the roost type, from known roosts in Białowieża village in the summers of 2016 and 2017. All handling procedures were approved by the General Directorate for Environmental Protection (permission number DZP-WG.6401.09.2.2014. $\mathrm{km}$ 6.03.2014) and the Local Ethics Committee for Animal Experimentation (permission number 11/2014). Our research protocol followed ASM guidelines (Sikes and Anim Care Use Comm Amer Soc 2016). We attached temperature transmitters (0.55 g BD-2XT, Holohil Systems Ltd, Carp, Ontario, Canada; 0.5 g PIP3, Biotrack Ltd, Wareham, United Kingdom) to the interscapular region of bats with skin adhesive (Hautkleber Sauer 50.01, Manfred Sauer GMBH, Lobbach, Germany). Mean mass of our bats was $12.4 \mathrm{~g} \pm 1.2 \mathrm{~g}$ and thus mass of the tags did not exceed the recommended 5\% threshold (Aldridge and Brigham 1988). We released bats directly after tagging and started localizing roosts and recording temperature next day until the transmitter fell off or the signal could no longer be found. We used 3-element Yagi antennas (Titley Scientific, Brendale, Australia), flexible and rigid 3-element antennas (Biotrack Ltd), and manual receivers (R1000, Communications Specialists Inc., Orange, California and FT 817 ND Yaesu, Cypress, California) to localize roosts. We localized bat roosts by "homing-in-onthe-animal" (White and Garrot 1990).

\section{Skin temperature measurements}

We recorded skin temperature as a proxy for body temperature continuously with the temperature-sensitive radio transmitters $(n=24)$ (Audet and Thomas 1996). We placed omnidirectional antennas (Biotrack Ltd., Dorset, UK) and logging receivers (SRX 800-D-1, Biotrack Ltd., Dorset, UK) near roosts to automatically register skin temperature of males continuously. We removed data from one individual measured during 1 day, where we had less than $13 \mathrm{~h}$ of continuous recordings from the analyses. Several tagged bats disappeared from our range before we were able to record them. This resulted in a final dataset from three bats during 10 bat days in 2016 and 14 bats during 55 bat days in 2017. We took 10-min means from the temperature data and calculated the torpor onset threshold for each bat day, i.e. measurement of skin temperature of one bat for 1 day (Willis 2007):

$$
\begin{aligned}
T_{\text {sk-onset }}-1 \mathrm{SE}= & (0.041) \times \text { body mass }+(0.04) \\
& \times \text { ambient temperature }+31.083
\end{aligned}
$$

We then calculated the heterothermy index (HI; Boyles et al. 2011), which describes the degree of skin temperature fluctuations, i.e. deviations from normothermy, for each bat day:

$\mathrm{HI}=\sqrt{\frac{\sum\left(T_{\text {sk-mod }}-T_{\text {sk-1 }}\right)^{2}}{n-1}}$

We assumed a bat was torpid if skin temperature dropped at least $0.1{ }^{\circ} \mathrm{C}$ below onset temperature for at least three consecutive readings (i.e. minimum $30 \mathrm{~min}$ ). The torpor depth was the maximum number of degrees that bat skin temperature dropped below onset temperature. Torpor duration was the total time that a bat remained torpid during 1 day (Rintoul and Brigham 2014). As the time between sunset and sunrise changed slightly over the field season (time of sunset varied from 20:21 to 20:39, sunrise from 4:15 to 4:49), we give results in hours before/after sunrise.

\section{Emergence observation}

We counted bats as they emerged from known roosts and from roosts with at least one bat with a transmitter on a given day to estimate group size. We observed emergence during 56 evenings (mid-May-July in both 2016 and 2017) from sunset until it was completely dark. Sex and species were identified based on the presence of tagged males and roost captures. We registered single females in male colonies occasionally, which may slightly bias the colony size estimations.

\section{Statistical analysis}

We applied a generalized additive model (GAM) using the gam function ("mgcv" package; Wood 2011) to test the effect of ambient temperature and time from sunrise on skin temperature. We added roost and bat ID as categorical random effects while they were sampled multiple times. Explanatory variables were weakly correlated $(r<0.43)$. We applied a linear mixed-effects model (LMM) using the lmer function ("Ime4" package; Bates et al. 2015) to test for the effect of environmental conditions on the heterothermy index. We added bat ID as a categorical random effect, as individuals were monitored multiple times. Explanatory variables were not correlated $(r<0.36)$. The global model included: the main effect of the mean ambient daily temperature from the day 
on which skin temperature was monitored, the mean number of insects (for all possible combinations) on the photos from the night before recordings, and the number of days since the beginning of the season (1st June). To test the effect of environmental variables on the number of bats in the roosts we applied a generalized additive model (GAM) using the gam function ("mgcv" package; Wood 2011) with Poisson distribution. Again, explanatory variables were not correlated $(r<0.34)$. The global model included environmental factors obtained the day before counting: the main effect of the mean ambient daily temperature, wind speed, rain intensity, and number of days since the beginning of the season. We added roost ID as a categorical random effect, as roosts were monitored multiple times. In both GAM models random effects were set as parametric terms penalized by a ridge penalty (Wood 2006). To find if there is a link between ambient temperature and preference for certain roost, or roost ID and the number of bats in this roost, we performed the generalized linear model (GLM) with Poisson distribution, which included main effects and interaction term between roost ID and ambient temperature. We selected only the roosts where bat emergence was observed more than five times. We used AIC to compare submodel including interaction term between roost ID and temperature with submodels with main effects of roost and temperature exclusively. We applied the Akaike information criterion (AIC) with a second-order correction for small sample size $\left(\mathrm{AIC}_{\mathrm{c}}\right.$ ) to rank all models using the dredge function ("MuMIn" package; Bartoń 2020). We assumed all submodels within $\triangle \mathrm{AIC}<2$ to have substantial support (Burnham and Anderson 2002). As in both GAM and LMM analyses only top-ranked submodels were withing assumed $\triangle \mathrm{AIC}$ range, they were selected as the best ones. All analyses were performed in $\mathrm{R}$ version 3.5.2 ( $\mathrm{R}$ Core Team 2018).

\section{Results}

\section{Insect abundance}

We collected 15,387 photos during ten insect survey sessions in 2016 from 25th May to 28th July (18 cameras in three habitats, once a week). Insects were present on $8 \%$ of them. In 2017 we monitored insects during 54 sessions (always with nine cameras in three habitats) from 30th May to 22nd July, and collected 39,418 photos. We registered insects on $20 \%$ of them (for details see Ruczyński et al. 2020). Insect availability during the study period was variable (Fig. 1).

\section{Capture and roost localizations}

We captured 248 males during the 2 years. Apart from one individual we mist-netted in the garden of the Mammal Research Institute in Białowieża, we caught all of them when

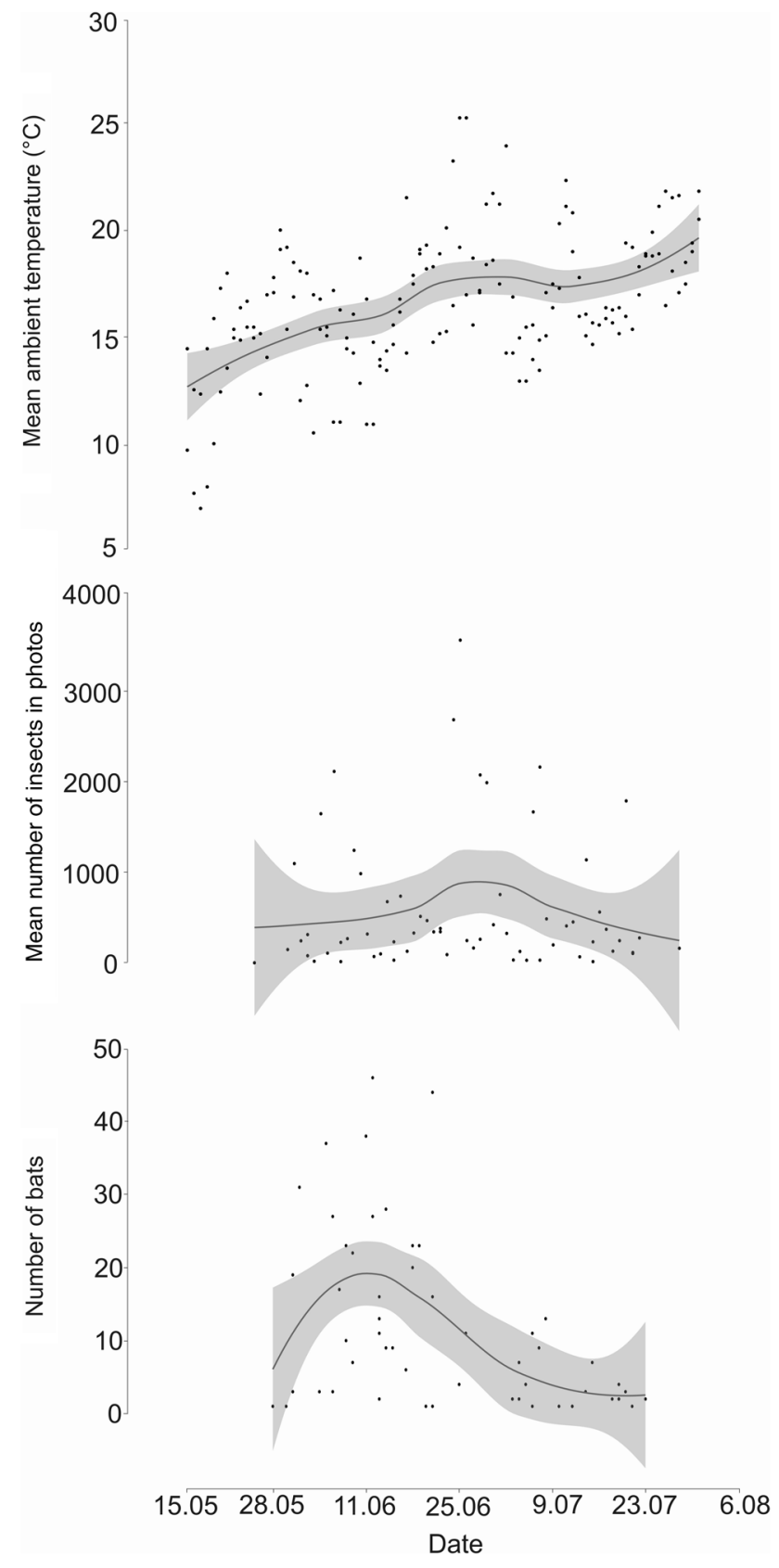

Fig. 1 Fluctuations of mean ambient temperature over time, mean number of insects in photos, and number of male parti-coloured bats in focal roosts in Białowieża Primaeval Forest, Poland, May-July 2016 and 2017

emerging from ten roosts. We localized a total 54 roosts, most of them in crevices in buildings of Białowieża (33) and rest in trees of the Białowieża Primaeval Forest. The bats used only six of those roosts during both years. Bats spent an average of 1.85 days $( \pm 1.46)$ in a given roost before switching to a new one, occasionally returning to previously used roosts. Two roosts where groups of bats were observed in 
summer 2016 were destroyed after the first season, because the buildings were renovated.

\section{Skin temperature measurements}

We obtained 65 bat days of skin temperature from 17 bats (three in 2016 and 14 in 2017). We excluded skin temperature data from 6 bat days in 2016 from the analyses of heterothermy index, for which we had no corresponding insect surveys. We also removed one record where the corresponding insect number was more than three times higher than the mean insect number. We observed the use of torpor on 58 of 65 bat days, during $37 \%$ of the time of all recordings. Mean duration of torpor was $429 \pm 225$ min per day, torpor depth $11^{\circ} \pm 5^{\circ} \mathrm{C}$ and the mean number of torpor bouts $2 \pm 1$. The modal value of skin temperature for all bat days was $34.3{ }^{\circ} \mathrm{C}$, while torpor onset temperature was $32.3 \pm 0.2{ }^{\circ} \mathrm{C}$ (Online Resource 1). All variables from the global skin temperature model were included in the best model (Online Resource 2a). Thermoregulatory patterns were correlated with time from sunrise (GAM, $P<0.001$, Fig. 2a, Online
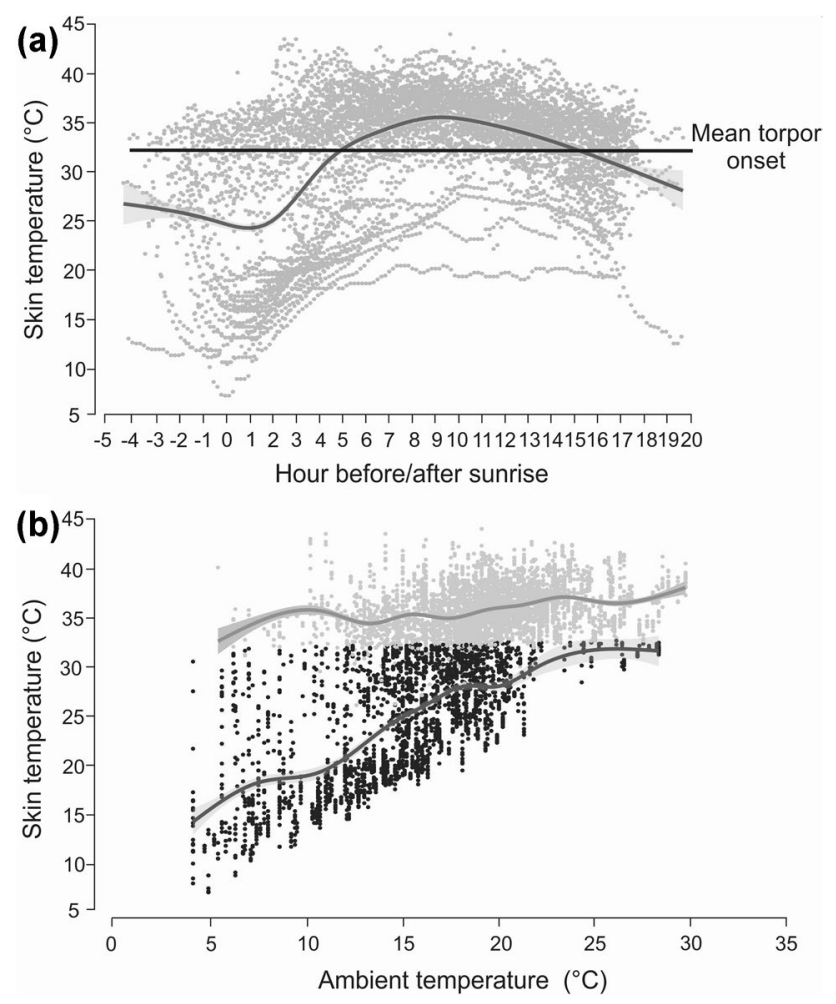

Fig. 2 Fluctuations of skin temperature (10-min mean temperature) of male parti-coloured bats in Białowieża Primaeval Forest, Poland, June-July 2016 and 2017 in relation to: a time from sunrise-black line represents mean torpor onset temperature $\left(\mathrm{T}_{\text {onset }}\right)$ calculated following Willis (2007). $P<0.001$, b ambient temperature-black dots represent heterothermy and grey normothermy [single recordings of skin temperature lower than torpor onset temperature were not classified as heterothermic (see "Materials and methods")]. $P<0.001$
Resource 2b) and ambient temperature (GAM, $P<0.001$, Fig. 2b, Online Resource 2b). We observed two daily peaks of low skin temperature/high heterothermy, one in the morning around 2-4 am and one in the evening around $8 \mathrm{pm}$ (Fig. 2a). The average $\mathrm{HI}$ was $6.36{ }^{\circ} \mathrm{C}\left( \pm 3.61{ }^{\circ} \mathrm{C}\right)$ and did not change significantly throughout the season. Thus, time since the beginning of the season was not significant and was not included in the best HI model (Online Resource 2a). This is probably due to the fact that our study only covered the early period of sperm production (see also Fig. 3, laboratory data from Komar et al. 2020). The heterothermy index was significantly higher at lower ambient temperatures (LMM, $P<0.001$, Fig. 4a, Online Resource 2b) and at lower insect abundance (LMM, $P=0.004$, Fig. $4 b$, Online Resource $2 b$ ).

\section{Emergence observations}

We focused our observations on roosts where tagged bats were currently roosting or roosts where large numbers of bats had previously been observed. We observed one to 46 bats per roost on a given evening (mean: 11, median: 7) (Fig. 1). Rain intensity had no influence on number of bats and it was excluded from the best model (Online Resource 2a). The number of bats per roost was higher at lower ambient temperatures and higher wind speeds (GAM, $P<0.001$ and $P<0.001$, Fig. 5, Online Resource $2 \mathrm{~b}$ ) and between day 19 and 29 of the season (16-26 June), after which the size of groups decreased rapidly (GAM, $P<0.001$, Online Resource 2b, see also Hałat et al. 2018). Relationship between bat

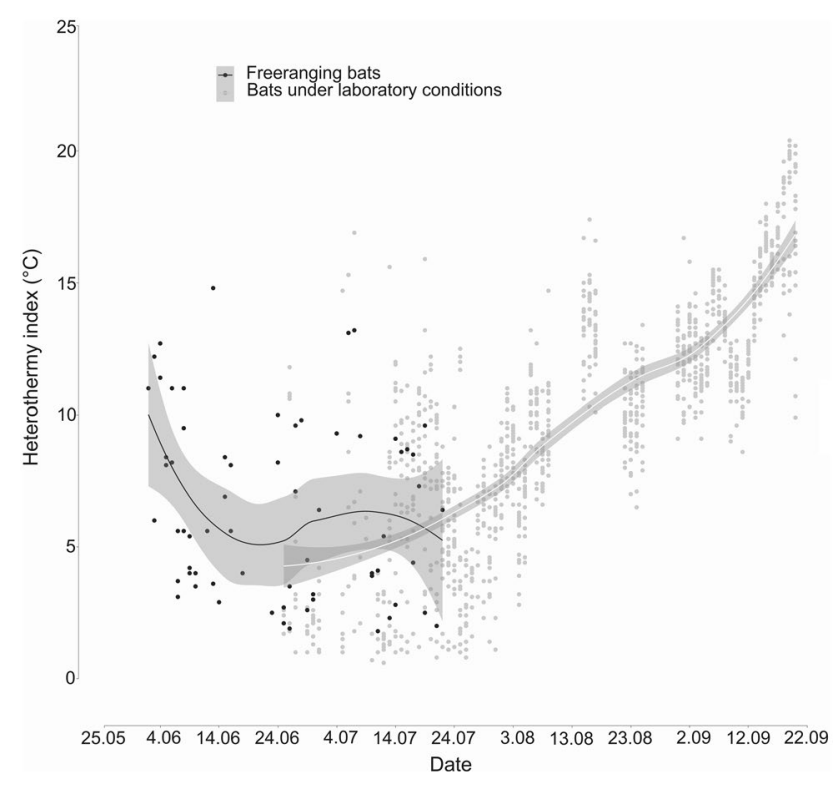

Fig. 3 Heterothermy index of parti-coloured bats: free-ranging males in Białowieża Primaeval Forest, Poland (June-July 2016 and 2017) and males under laboratory conditions (June-September 2016) (Laboratory data from Komar et al. 2020) 

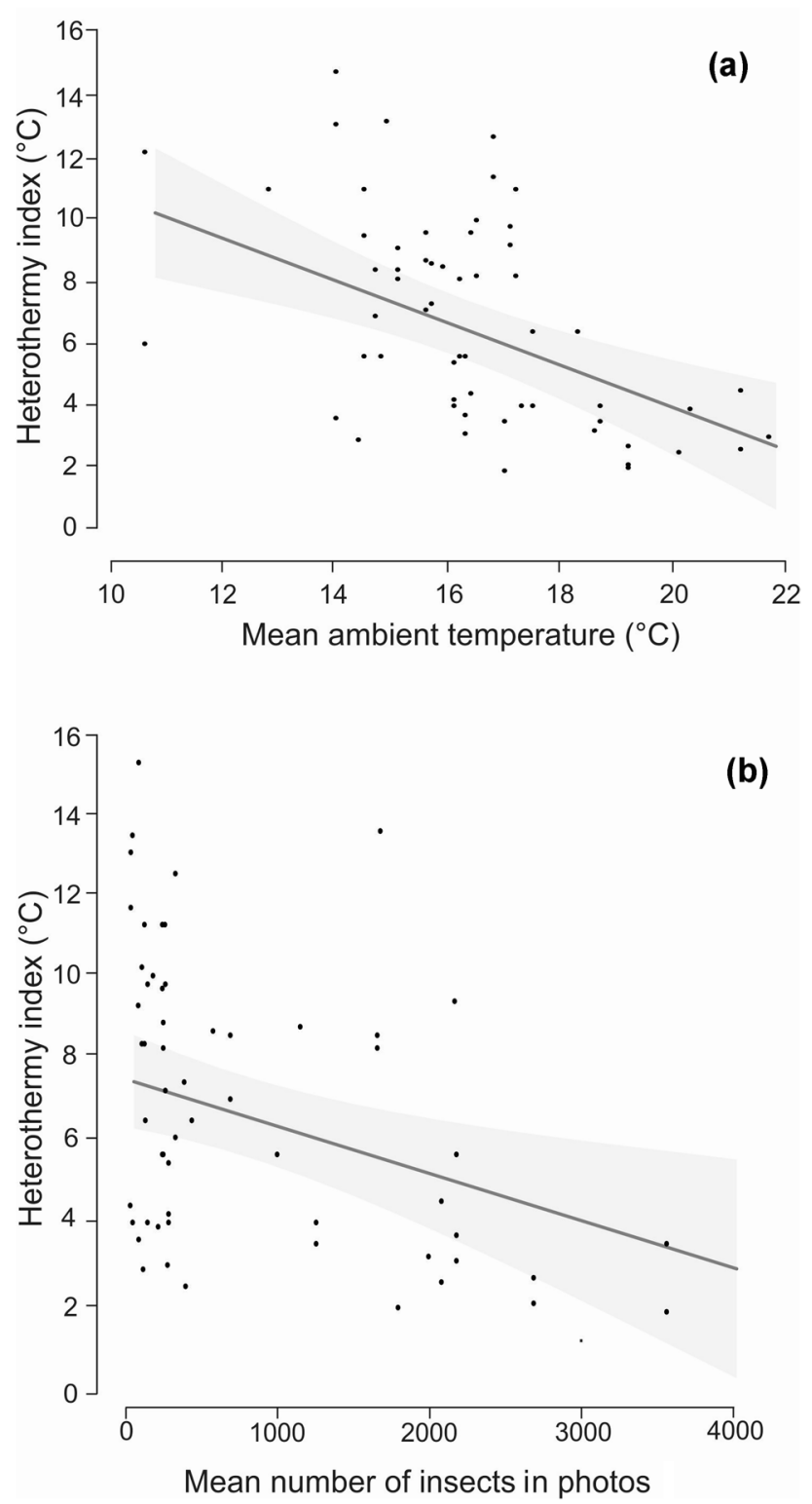

Fig. 4 Relationship between heterothermy index of male parti-coloured bats and: a ambient temperature $(P<0.001)$, b insect abundance $(P=0.004)$ in Białowieża Primaeval Forest, Poland, June-July 2016 and 2017

number and ambient temperature was not connected with roost preference. AIC-based comparison of GLM submodels revealed that submodel that included interaction of roost ID and ambient temperature was ranked significantly lower than any of the submodels that included different combination of main effects ( $\triangle \mathrm{AIC}>5$, Online Resource 2a, b, Fig. 6).

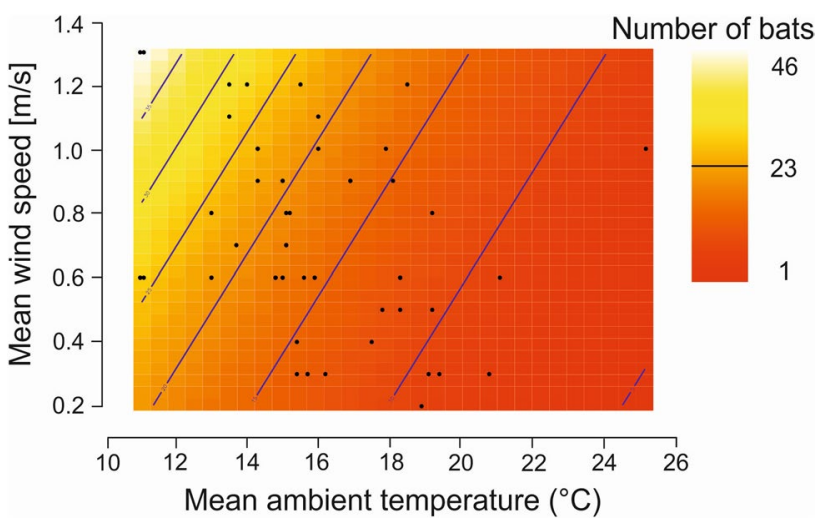

Fig. 5 Relationship between mean ambient temperature, wind speed and number of male parti-coloured bats in roosts in Białowieża Primaeval Forest, Poland, June-July 2016 and 2017, $P<0.001$ and $P<0.001$

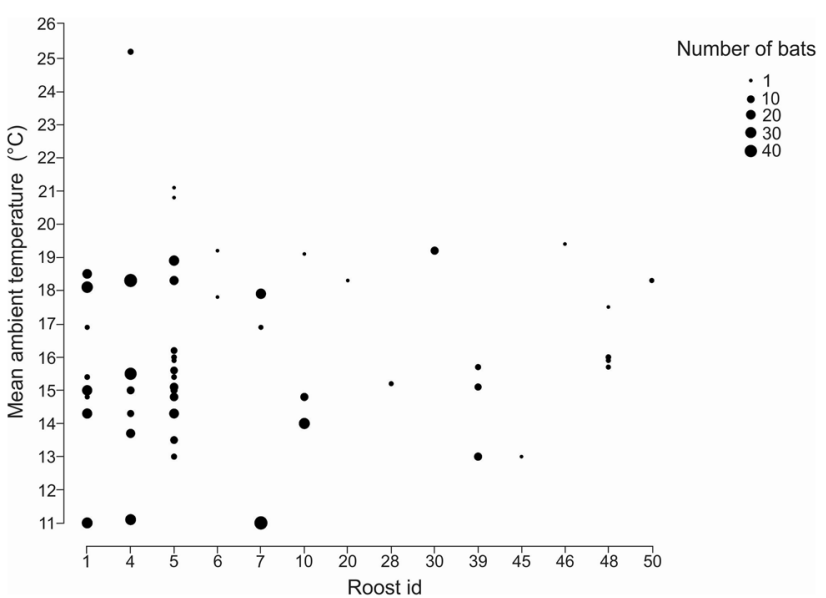

Fig. 6 Number of male parti-coloured bats in focal roosts in relation to ambient temperature, Białowieża Primaeval Forest, Poland, JuneJuly 2016 and 2017

\section{Discussion}

Social warming and the use of torpor are alternative mechanisms of energy conservation bats use under poor weather conditions (Speakman and Thomas 2003; Willis and Brigham 2007), that have been observed in pregnant, lactating as well as non-reproductive females and males (Lausen and Barclay 2003; Dietz and Kalko 2006; Pretzlaff et al. 2010; Dzal and Brigham 2013; Johnson and Lacki 2014). We provide an assessment of behavioural and physiological strategies of how male bats deal with adverse environmental factors. Our results, revealed larger groups of males during adverse weather conditions, but no preference for specific roosts depending on weather conditions, which may indicate that social warming and/or information transfer about 
ephemeral food resources may promote sociality in male bats. Contrary to our expectations, males did use torpor in spite of ongoing sperm production. For comparison (Fig. 3; laboratory data from Komar et al. 2020) captive males of the same species showed similar levels of torpor use at ambient temperatures during the time period our study covered, compared to much higher levels later in the year when sperm maturation was completed [corresponding to the moment when males become solitary again in nature (Halat et al. 2018)].

Our results support our expectation that weather conditions influenced the number of males in groups. We observed significantly more bats in roosts at lower ambient temperature and higher wind speed. However, we did not find a link between ambient temperature and a preference for certain roosts, or roost ID and the number of bats in this roost (Fig. 6), both of which would indicate that bats simply accumulate in colder roosts during adverse conditions to profit from deeper torpor. In addition to profound day-to-day fluctuations in group size caused by the weather conditions, we also observed long-term changes in maximum group size over a longer time period (Mazurska and Ruczyński 2008; Hałat et al. 2018). The smallest male groups were recorded in 2019 (Online Resource 3), during the hottest June in 140 years of temperature recordings (Scutti 2019), when mean ambient temperature in Białowieża was $21^{\circ} \mathrm{C}$, while the largest groups were observed in the years with colder June temperatures (data from Polish Institute of Meteorology and Water Management-National Research Institute).

Social aggregation is thought to lead to energy saving in bats, because of the warming effect of larger numbers of individuals (Willis and Brigham 2007). For example, female Bechstein's bats (Myotis bechsteinii) form larger groups during pregnancy and use less torpor. They form smaller groups after the young are weaned and revert to using torpor more often (Pretzlaff et al. 2010). Similarly, female barbastelle bats (Barbastella barbastellus) form larger groups to reduce torpor (Russo et al. 2017). Thus, we expected that male parti-coloured bats, too, gather in larger groups to maintain normothermy during sperm production. Due to methodological limitations, we were almost never able to observe the bats inside their roosts and determine whether they roosted in clusters, as would be necessary for social thermoregulation, but analysis of data from seven bat days for which group size and skin temperature were available, resulted in a positive correlation of these parameters, supporting our hypothesis (Online Resource 4).

The results from the insect monitoring support a link between colonial life style in males and ambient conditions during sperm production as well. On the one hand, lower insect availability and thus presumably lower energy intake may force the bats to roost in groups and profit from social thermoregulation. In addition, they may gather in groups to use information transfer about ephemeral food resources and forage more efficiently during low food availability. Insects are less abundant at lower temperatures and higher wind speed (Speakman et al. 2000; Ashdown and McKechnie 2008; Gruebler et al. 2008; Lutz et al. 2019; Ruczyński et al. 2020), and thus more difficult and inefficient to find for bats. It was not possible to include insect abundance in the group size model due to the structure of the insect survey dataset, but we show an overview of these results (Fig. 1). The highest numbers of bats in roosts in both years preceded the peak of insect abundance. This indicates that insect abundance may shape group size. Mean wind speed was low during the study period $(0-1.4 \mathrm{~m} / \mathrm{s})$ and it is unlikely that it had a direct impact on the bats, but it may have affected insect activity and thus the bats indirectly. Foraging on ephemeral insects in poor weather conditions may become inefficient, when the effort invested into flight during solitary foraging is higher than the energetic intake of insects. Under these conditions, males may revert to social foraging to profit from information transfer and to facilitate this they become more social. They may then coordinate flight to foraging sites, where information transfer usually takes place as has been shown for other species (Dechmann et al. 2009, 2010; EgertBerg et al. 2018). As male parti-coloured bats forage far from their roosts (median $5 \mathrm{~km}$, maximum $17.8 \mathrm{~km}$ ) (Safi et al. 2007) such coordinated flight may be necessary as bats would be scattered too widely across the landscape to make opportunistic eavesdropping sufficient. Effective social warming and cooperative foraging can mitigate the negative direct and indirect effects of poor weather conditions, but may not always be sufficient to bridge periods of poor resource availability. Under such circumstances, additional physiological mechanisms such as torpor may be necessary, even during reproduction to balance daily energy budgets.

And indeed, our bats used torpor, even if at relatively low levels, more frequently on colder days and when insect abundance was low. We expected that while roosting in larger groups males should avoid torpor almost completely during testes maturation, to maintain the process of sperm production and growth of reproductive tissue (Racey and Swift 1981; Entwistle et al. 1998; Wilde et al. 1999). Instead, the heterothermy index was independent of the day of the season and thus torpor use was not affected by the status of reproductive maturation, at least under the observed range of fluctuation in conditions. However, males did tend to stay normothermic (see also Komar et al. 2020; Fig. 3; laboratory data from Komar et al. 2020). Our bats expressed only few instances of deep and long torpor use (Online Resource 5), but, even short periods of shallow torpor may be crucial for their energy budgets (Studier 1981; Webb et al. 1993). Our study period fully overlapped with the development of reproductive tissues in free-ranging (Safi 2008; Hałat et al. 2018) and captive males (Komar et al. 2020). 
Captive male parti-coloured bats begin to use torpor more frequently again, when sperm production is advanced, i.e. at the beginning of August (Komar et al. 2020). Solitary male Daubenton's bats during sexual maturation and the time of the highest relative insect abundance increase energy intake and reduce torpor use resulting in a heterothermy index that is comparable with our results $\left(6.3^{\circ} \pm 1.5^{\circ} \mathrm{C}\right)$. However, before and after sperm production they use torpor more intensively (Becker et al. 2013).

Clearly, bats do revert to using torpor, even during reproduction, if weather conditions become harsh and foraging is unpredictable, e.g. male Daubenton's (Dietz and Kalko 2006) and big brown bats Eptesicus fuscus (Grinevitch et al. 1995) or females during pregnancy and lactation, e. g. in pipistrelle (Pipistrellus pipistrellus) (Racey and Swift 1981) and hoary bats Lasiurus cinereus (Hickey and Fenton 1996). Obtaining skin temperature data from free-ranging particoloured bats after the colonies dissolve (August-September) would help answer the question if males change their physiological response to adverse weather conditions, when sperm is already partially or fully produced in the field, similar to what was observed in the lab (Komar et al. 2020). Safi (2008) reported that males in lower physical condition and lower level of reproductive tissues development remained in colonies longer than males in better condition. This makes sense as males in good condition, which have completed sperm maturation, should prefer to be solitary. This would allow them to increase torpor use, which is beneficial for sperm storage (Racey 1972; Geiser and Brigham 2012) and regulate torpor use independently of others and according to their personal foraging success during the previous night.

Roost microclimate can also explain the occurrence of larger colonies in poor weather conditions (Webber and Willis 2018). However, this is unlikely in case of male parti-coloured bats. Once we observed clustering inside the roost, which should not happen if roost climate rather than social warming were the reason to aggregate. Moreover, we observed dawn swarming in front of the roosts, which is a behaviour known to inform others about roost locations and aid group decision making about roost selection (Nad'o and Kanuch 2013, 2015). Alternatively, if suitable roosts were rare, sociality could be the effect of roost selection preferences of individuals (Kerth 2008). Female bats choose their roost based on temperature and humidity (Sedgeley 2001; Lausen and Barclay 2003; Smith and Racey 2005; Ruczyński 2006), but Willis and Brigham (2007) showed that roost microclimate is less important than the number of bats occupying a roost. Safi and Kerth (2008) in their review on sociality in male bats from the temperate zone, did not consider roost scarcity as a potential reason for male aggregations, because males of these species roost in various types of roosts (tree bark, tree cavities, buildings and caves).
In our study we found a large number of roosts and frequent roost switching, which indicates that roosts were not limited.

Our previous work (Hałat et al. 2018) showed that male parti-coloured bats forage during shorter periods when insect abundance is lower. They then probably use torpor to compensate for this. Bats also spent less time outside their roosts foraging when they were living in colonies. This is consistent with the assumption that bats in larger groups take advantage of group foraging and search for insects more efficiently, even in poor weather. Torpor may be a last resort during sexual maturation, when insect scarcity and poor weather conditions make foraging difficult. It is possible that during such times, males then form colonies to take advantage of social warming or information transfer about insect swarms. We expected that only if this strategy is not sufficient either, bats should use torpor, as this inhibits reproductive processes (Komar et al. 2020).

In summary, our results add weight to the hypothesis that compensating for the direct and indirect effects of poor weather conditions may promote the formation of colonies not only in female temperate zone bats during pregnancy and lactation, but also in males of species that strongly depend on ephemeral insect swarms during sperm production and maturation. This may allow them to compensate for poor foraging success and/or increase foraging efficiency through passive information transfer, while minimizing energy spent on maintaining normothermy and thus getting ready for the mating season sooner.

Acknowledgements We thank our friends, students and volunteers for much appreciated help in the field: M. Tulejko, M. Wróbel, L. Contreras Peinado, J. Metselaar, D. Oosterholt, M. Ziobrowska, E. Łepkowska, R. Proost, A. E. J. Visser and A. Smugała. We are grateful to E. Komar for her overall help as well as N. Fasel, T. Borowik and M. Żmihorski for their help in statistical analyses and J. Rintoul for her interesting tips of dealing with this kind of data and two anonymous reviewers for their comments. We also thank K. Zub for lending us equipment and all local people who allowed us to conduct our study on their properties.

Author contributions ZH, DKND and IR conceived ideas and designed methodology, $\mathrm{ZH}, \mathrm{MZ}$ and IR collected data; $\mathrm{ZH}$ analysed data; $\mathrm{ZH}$ and DKND led writing of paper; IR obtained funding. All authors contributed critically to the drafts and gave final approval for publication.

Funding This work was founded by the Polish National Science Centre on the basis of decision number DEC-2013/10/E/NZ8/00725.

\section{Compliance with ethical standards}

Conflict of interest The authors declare that they have no conflict of interest, financial or other, exist.

Ethical approval All handling procedures were approved by the General Directorate for Environmental Protection (permission number DZP-WG.6401.09.2.2014.km 6.03.2014) and the Local Ethics Committee for Animal Experimentation (permission number 11/2014). 
Open Access This article is licensed under a Creative Commons Attribution 4.0 International License, which permits use, sharing, adaptation, distribution and reproduction in any medium or format, as long as you give appropriate credit to the original author(s) and the source, provide a link to the Creative Commons licence, and indicate if changes were made. The images or other third party material in this article are included in the article's Creative Commons licence, unless indicated otherwise in a credit line to the material. If material is not included in the article's Creative Commons licence and your intended use is not permitted by statutory regulation or exceeds the permitted use, you will need to obtain permission directly from the copyright holder. To view a copy of this licence, visit http://creativecommons.org/licenses/by/4.0/.

\section{References}

Aldridge H, Brigham RM (1988) Load carrying and maneuverability in an insectivorous bat - a test of the 5-percent rule of radiotelemetry. J Mammal 69:379-382

Alexander RM (2002) The merits and implications of travel by swimming, flight and running for animals of different sizes. ICB 42:1060-1064

Anthony ELP, Kunz TH (1977) Feeding strategies of little brown bat, Myotis lucifugus, in Southern New Hampshire. Ecology 58:775-786

Ashdown RAM, McKechnie AE (2008) Environmental correlates of freckled nightjar (Caprimulgus tristigma) activity in a seasonal, subtropical habitat. J Ornithol 149:615-619

Audet D, Thomas DW (1996) Evaluation of the accuracy of body temperature measurement using external radio transmitters. Can J Zool 74:1778-1781

Bartoń K (2020) MuMIn: multi-model Inference. R package version 1.43.17. https://CRAN.R-project.org/package=MuMIn. Accessed 1 Apr 2020

Bates D, Machler M, Bolker BM, Walker SC (2015) Fitting linear mixed-effects models using lme4. J Stat Softw 67:1-48

Becker NI, Tschapka M, Kalko EKV, Encarnacao JA (2013) Balancing the energy budget in free-ranging male Myotis daubentonii bats. Physiol Biochem Zool 86:361-369

Begon M, Townsend CR, Harper JL (2005) Ecology: from individuals to ecosystem, 4th edn. Wiley-Blackwell, New York

Boratyński JS, Iwińska K, Bogdanowicz W (2018) Body temperature variation in free-living and food-deprived yellow-necked mice sustains an adaptive framework for endothermic thermoregulation. Mammal Res 63:493-500

Boyles JG, Dunbar MB, Storm JJ, Brack V (2007) Energy availability influences microclimate selection of hibernating bats. J Exp Biol 210:4345-4350

Boyles JG, Smit B, McKechnie AE (2011) A new comparative metric for estimating heterothermy in endotherms. Physiol Biochem Zool 84:115-123

Burnham KP, Anderson DR (2002) Model selection and multimodel inference: a practical information-theoretic approach. Springer, New York

Cvikel N, Berg KE, Levin E, Hurme E, Borissov I, Boonman A, Amichai E, Yovel Y (2015) Bats aggregate to improve prey search but might be impaired when their density becomes too high. Curr Biol 25:206-211

Dechmann DKN, Heucke SL, Giuggioli L, Safi K, Voigt CC, Wikelski M (2009) Experimental evidence for group hunting via eavesdropping in echolocating bats. Proc Biol Sci 276:2721-2728
Dechmann DKN, Kranstauber B, Gibbs D, Wikelski M (2010) Group hunting - a reason for sociality in molossid bats? PLoS ONE 5(2): 99012

Dietz M, Kalko EKV (2006) Seasonal changes in daily torpor patterns of free-ranging female and male Daubenton's bats (Myotis daubentonii). J Comp Physiol B Biochem Syst Environ Physiol 176:223-231

Dzal YA, Brigham RM (2013) The tradeoff between torpor use and reproduction in little brown bats (Myotis lucifugus). J Comp Physiol B Biochem Syst Environ Physiol 183:279-288

Egert-Berg K, Hurme ER, Greif S, Goldstein A, Harten L, Luis GHM, Flores-Martinez JJ, Valdes AT, Johnston DS, Eitan O, Borissov I, Shipley JR, Medellin RA, Wilkinson GS, Goerlitz HR, Yovel Y (2018) Resource ephemerality drives social foraging in bats. Curr Biol 28:3667-3673.e5

Entwistle AC, Racey PA, Speakman JR (1998) The reproductive cycle and determination of sexual maturity in male brown long-eared bats, Plecotus auritus (Chiroptera: Vespertilionidae). J Zool 244:63-70

Gager Y (2019) Information transfer about food as a reason for sociality in bats. Mammal Rev 49:113-120

Geiser F, Brigham RM (2012) The other functions of torpor. In: Ruf T, Bieber C, Arnold W, Millesi E (eds) Living in a seasonal world. Springer, Heidelberg, pp 109-121

Grinevitch L, Holroyd SL, Barclay RMR (1995) Sex-differences in the use of daily torpor and foraging time by big brown bats (Eptesicus fuscus) during the reproductive season. J Zool 235:301-309

Gruebler MU, Morand M, Naef-Daenzer B (2008) A predictive model of the density of airborne insects in agricultural environments. Agric Ecosyst Environ 123:75-80

Hałat Z, Dechmann DKN, Zegarek M, Visser AFJ, Ruczyński I (2018) Sociality and insect abundance affect duration of nocturnal activity of male parti-colored bats. J Mammal 99:1503-1509

Hickey MBC, Fenton MB (1996) Behavioural and thermoregulatory responses of female hoary bats, Lasiurus cinereus (Chiroptera: Vespertilionidae), to variations in prey availability. Ecoscience 3:414-422

Johnson JS, Lacki MJ (2014) Effects of reproductive condition, roost microclimate, and weather patterns on summer torpor use by a vespertilionid bat. Ecol Evol 4:157-166

Kerth G (2008) Causes and consequences of sociality in bats. Bioscience 58:737-746

Kerth G, Weissmann K, Konig B (2001) Day roost selection in female Bechstein's bats (Myotis bechsteinii): a field experiment to determine the influence of roost temperature. Oecologia 126:1-9

Komar E, Dechmann DKN, Fasel NJ , Zegarek M, Ruczyński I (2020) Food restriction delays seasonal sexual maturation but does not increase torpor use in male bats. J Exp Biol 223:jeb214825. https ://doi.org/10.1242/jeb.214825

Krutzsch PH (2000) Anatomy, physiology and cyclicity of the male reproductive tract. In: Crichton EG, Krutzsch PH (eds) Reproductive biology of bats. Academic Press, London, pp 91-155

Kurta A, Kunz TH (1988) Roosting metabolic rate and body temperature of male little brown bats (Myotis lucifugus) in summer. J Mammal 69:645-651

Kurta A, Johnson KA, Kunz TH (1987) Oxygen consumption and body temperature of female little brown bats (Myotis lucifugus) under simulated roost conditions. Physiol Zool 60:386-397

Lane JE, Boutin S, Speakman JR, Humphries MM (2010) Energetic costs of male reproduction in a scramble competition mating system. J Anim Ecol 79:27-34

Lausen CL, Barclay RMR (2003) Thermoregulation and roost selection by reproductive female big brown bats (Eptesicus fuscus) roosting in rock crevices. J Zool 260:235-244 
Lutz L, Verhoff MA, Amendt J (2019) Environmental factors influencing flight activity of forensically important female blow flies in Central Europe. Int J Leg Med 133:1267-1278

Mazurska K, Ruczyński I (2008) Bats select buildings in clearings in Białowieża Primeval Forest. Acta Chiropterol 10:331-338

McNab BK (1983) Energetics, body size, and the limits to endothermy. J Zool 199:1-29

Nad'o L, Kanuch P (2013) Dawn swarming in tree-dwelling bats - an unexplored behaviour. Acta Chiropterol 15:387-392

Nad'o L, Kanuch P (2015) Swarming behaviour associated with group cohesion in tree-dwelling bats. Behav Process 120:80-86

Pretzlaff I, Kerth G, Dausmann KH (2010) Communally breeding bats use physiological and behavioural adjustments to optimise daily energy expenditure. Naturwissenschaften 97:353-363

R Core Team (2018) R: a language and environment for statistical computing. R Foundation for Statistical Computing, Vienna, Austria

Racey PA (1972) Viability of bat spermatozoa after prolonged storage in the epididymis. J Reprod Fertil 28:309-311

Racey PA, Speakman J (1987) The energy costs of pregnancy and lactation in heterothermic bats. Symp Zool Soc Lond 57:107-125

Racey PA, Swift SM (1981) Variations in gestation length in a colony of pipistrelle bats (Pipistrellus pipistrellus) from year to year. $\mathrm{J}$ Reprod Fertil 61:123-129

Rintoul JLP, Brigham RM (2014) The influence of reproductive condition and concurrent environmental factors on torpor and foraging patterns in female big brown bats (Eptesicus fuscus). J Comp Physiol B Biochem Syst Environ Physiol 184:777-787

Ruczyński I (2006) Influence of temperature on maternity roost selection by noctule bats (Nyctalus noctula) and Leisler's bats (N leisleri) in Białowieża Primeval Forest, Poland. Can J Zool 84:900-907

Ruczyński I, Hałat Z, Zegarek M, Borowik T, Dechmann DKN (2020) Camera transects as a method to monitor high temporal and spatial ephemerality of flying nocturnal insects. Methods Ecol Evol 11:294-302

Ruf T, Bieber C, Arnold W, Millesi E (2012) Living in a seasonal world. Thermoregulatory and metabolic adaptations. Springer, Berlin

Russo D, Cistrone L, Budinski I, Console G, Della Corte M, Milighetti C, Di Salvo I, Nardone V, Brigham RM, Ancillotto L (2017) Sociality influences thermoregulation and roost switching in a forest bat using ephemeral roosts. Ecol Evol 7:5310-5321

Rydell J, Baagøe DHJ (1994) Vespertilio murinus. Mamm Species 467:1-6

Safi K (2008) Social bats: the males' perspective. J Mammal 89:1342-1350

Safi K, Kerth G (2007) Comparative analyses suggest that information transfer promoted sociality in male bats in the temperate zone. Am Nat 170:465-472

Safi K, Koenig B, Kerth G (2007) Sex differences in population genetics, home range size and habitat use of the parti-colored bat (Vespertilio murinus, Linnaeus 1758) in Switzerland and their consequences for conservation. Biol Conserv 137:28-36

Scutti S (2019) Worldwide, June 2019 was the hottest june ever, according to more than a century of weather records. https://editi on.cnn.com/2019/07/19/us/june-2019-hottest-on-record/index .html. Accessed 31 Jan 2020

Sedgeley JA (2001) Quality of cavity microclimate as a factor influencing selection of maternity roosts by a tree-dwelling bat, Chalinolobus tuberculatus, in New Zealand. J Appl Ecol 38:425-438

Sikes RS, Anim Care Use Comm Amer Soc M (2016) 2016 guidelines of the American Society of Mammalogists for the use of wild mammals in research and education. J Mammal 97:663-688

Smith PG, Racey PA (2005) The itinerant Natterer: physical and thermal characteristics of summer roosts of Myotis nattereri (Mammalia: Chiroptera). J Zool 266:171-180

Speakman JR, Thomas DW (2003) Physiological ecology and energetics of bats. In: Kunz TH, Fenton MB (eds) Bat ecology. The University of Chicago, Chicago

Speakman JR, Rydell J, Webb PI, Hayes JP, Hays GC, Hulbert IAR, McDevitt RM (2000) Activity patterns of insectivorous bats and birds in northern scandinavia $\left(69^{\circ} \mathrm{N}\right)$, during continuous midsummer daylight. Oikos 88:75-86

Studier EH (1981) Energetic advantages of slight drops in body temperature in little brown bat, Myotis lucifugus. Comp Biochem Phys A 70:537-540

Terrien J, Perret M, Aujard F (2011) Behavioral thermoregulation in mammals: a review. Front Biosci 16:1428-1444

Tuttle MD, Stevenson D (1982) Growth and survival. In: Kunz TH (ed) Ecology of bats. Springer, Boston, pp 105-150

Webb PI, Speakman JR, Racey PA (1993) The implication of small reductions in body temperature for radiant and convective heat loss in resting endothermic brown long eared bats (Plecotus auritus). J Therm Biol 18:131-135

Webber QMR, Willis CKR (2018) An experimental test of effects of ambient temperature and roost quality on aggregation by little brown bats (Myotis lucifugus). J Therm Biol 74:174-180

White GC, Garrot RA (1990) Analysis of wildlife radio-tracking data. Academic Press, San Diego

Wilde CJ, Knight CR, Racey PA (1999) Influence of torpor on milk protein composition and secretion in lactating bats. J Exp Zool 284:35-41

Williams CB (1961) Studies in the effect of weather conditions on the activity and abundance of insect populations. Philos Trans R Soc B 244:331-378

Willis CKR (2007) An energy-based body temperature threshold between torpor and normothermia for small mammals. Physiol Biochem Zool 80:643-651

Willis CKR, Brigham RM (2007) Social thermoregulation exerts more influence than microclimate on forest roost preferences by a cavity-dwelling bat. Behav Ecol Sociobiol 62:97-108

Wood SN (2006) Generalized additive models: an introduction with R. Texts in statistical science. Chapman \& Hall/CRC, Boca Raton

Wood SN (2011) Fast stable restricted maximum likelihood and marginal likelihood estimation of semiparametric generalized linear models. J R Stat Soc Ser B Stat Methodol 73:3-36

Publisher's Note Springer Nature remains neutral with regard to jurisdictional claims in published maps and institutional affiliations. 